\title{
Article \\ Immunoproteasome Activity in Chronic Lymphocytic Leukemia as a Target of the Immunoproteasome-Selective Inhibitors
}

\author{
Andrej Besse ${ }^{1}$, Marianne Kraus ${ }^{1}$, Max Mendez-Lopez ${ }^{1}$, Elmer Maurits ${ }^{2} \mathbb{D}$, Herman S. Overkleeft ${ }^{2}$, \\ Christoph Driessen ${ }^{1}$ and Lenka Besse ${ }^{1, * \mathbb{D}}$ \\ 1 Laboratory of Experimental Oncology, Department of Oncology and Hematology, Cantonal Hospital \\ St. Gallen, 9000 St. Gallen, Switzerland; andrej.besse@kssg.ch (A.B.); marianne.kraus@kssg.ch (M.K.); \\ max.mendezlopez@kssg.ch (M.M.-L.); christoph.driessen@kssg.ch (C.D.) \\ 2 Gorlaeus Laboratories, Leiden Institute of Chemistry, 2333 CC Leiden, The Netherlands; \\ e.maurits@lic.leidenuniv.nl (E.M.); h.s.overkleeft@lic.leidenuniv.nl (H.S.O.) \\ * Correspondence: lenka.besse@kssg.ch
}

check for updates

Citation: Besse, A.; Kraus, M.; Mendez-Lopez, M.; Maurits, E.; Overkleeft, H.S.; Driessen, C.; Besse, L. Immunoproteasome Activity in Chronic Lymphocytic Leukemia as a Target of the ImmunoproteasomeSelective Inhibitors. Cells 2022, 11, 838. https://doi.org/10.3390/ cells11050838

Academic Editor: Yusuke Furukawa

Received: 27 January 2022 Accepted: 22 February 2022 Published: 1 March 2022

Publisher's Note: MDPI stays neutral with regard to jurisdictional claims in published maps and institutional affiliations.

Copyright: (C) 2022 by the authors. Licensee MDPI, Basel, Switzerland. This article is an open access article distributed under the terms and conditions of the Creative Commons Attribution (CC BY) license (https:// creativecommons.org/licenses/by/ $4.0 /)$.

\begin{abstract}
Targeting proteasome with proteasome inhibitors (PIs) is an approved treatment strategy in multiple myeloma that has also been explored pre-clinically and clinically in other hematological malignancies. The approved PIs target both the constitutive and the immunoproteasome, the latter being present predominantly in cells of lymphoid origin. Therapeutic targeting of the immunoproteasome in cells with sole immunoproteasome activity may be selectively cytotoxic in malignant cells, while sparing the non-lymphoid tissues from the on-target PIs toxicity. Using activity-based probes to assess the proteasome activity profile and correlating it with the cytotoxicity assays, we identified B-cell chronic lymphocytic leukemia (B-CLL) to express predominantly immunoproteasome activity, which is associated with high sensitivity to approved proteasome inhibitors and, more importantly, to the immunoproteasome selective inhibitors LU005i and LU035i, targeting all immunoproteasome active subunits or only the immunoproteasome $\beta 5 \mathrm{i}$, respectively. At the same time, LU102, a proteasome $\beta 2$ inhibitor, sensitized B-CLL or immunoproteasome inhibitor-inherently resistant primary cells of acute myeloid leukemia, B-cell acute lymphoblastic leukemia, multiple myeloma and plasma cell leukemia to low doses of LU035i. The immunoproteasome thus represents a novel therapeutic target, which warrants further testing with clinical stage immunoproteasome inhibitors in monotherapy or in combinations.
\end{abstract}

Keywords: immunoproteasome; chronic lymphocytic leukemia; acute myeloid leukemia; multiple myeloma; plasma cell leukemia; proteasome inhibitors; LU005i; LU035i; activity-based probes; proteasome activity

\section{Introduction}

The differentiation of human B-cells from their progenitors to immunoglobulinsecreting cells is completed in a series of clearly recognized, discrete stages. At each step of the B-cell differentiation, a cell can undergo malignant transformation, thus giving rise to various malignancies arising from the B-cell lineage. Poorly differentiated acute B-cell malignancies, such as B-cell acute lymphoblastic leukemia (B-ALL) are more common in children than in adults, while the most prevalent B-cell malignancies in adults are chronic lymphocytic leukemia (B-CLL) or malignancies of terminally differentiated plasma cells, such as multiple myeloma (MM) or plasma-cell leukemia (PCL). While B-CLL is the most common chronic type of leukemia in adults, the most common type of acute leukemia in adults is acute myeloid leukemia (AML), a malignancy arising from a myeloid progenitor (National Cancer Institute: https: / / seer.cancer.gov accessed on 20 January 2022).

The treatment of these hematological malignancies has considerably improved in the past years with the recent approval of several novel agents for the treatment of AML, B-ALL, $\mathrm{B}$-CLL and MM, which contributed to expanding the palette of therapeutic options in these 
diseases [1-4]. However, the main reason for treatment failure in a significant proportion of adult patients with leukemias or MM is the occurrence of intrinsic or acquired drug resistance in a subset of malignant cells that is responsible for the development of relapse or refractory disease with a dismal prognosis [5-8]. Subsequently, as the development of drug resistance is one of the limiting factors affecting long-term efficacy of anti-leukemic or anti-myeloma drugs, the search for therapies with novel mechanisms of action is an ongoing challenge.

Proteasome inhibitors (PIs), such as boronate-based bortezomib and ixazomib and epoxyketone-based carfilzomib specifically inhibit proteasomes, which are large protein complexes with three main catalytic subunits $\beta 1, \beta 2$ and $\beta 5$, providing the proteasome with caspase-like, trypsin-like and chymotrypsin-like activities to digest and recycle ubiquitintagged proteins [9]. By design, PIs bind to the active pocket of the proteasome $\beta 5$ subunit, which was initially identified as a rate-limiting protease for functional proteasomal degradation. Only recently, the importance of other proteasome subunits has been shown. The proteasome $\beta 5$ subunit allosterically activates the $\beta 1$ subunit [9-11], but its co-inhibition has not shown a strong additional cytotoxic effect, whereas the functional $\beta 2$ subunit co-inhibition together with $\beta 5$ inhibition is cytotoxic in $\mathrm{MM}$ and breast cancer cells [12-14].

PIs are cornerstones of treatment of plasma cell malignancies, such as MM, PCL, and mantle cell lymphoma [15]. Moreover, they were extensively evaluated for the therapy of other myeloid or lymphoid malignancies. Although the pre-clinical data showed efficacy of PIs bortezomib and carfilzomib in B-CLL [16-19], AML [20,21] and ALL [22], clinical observations of PIs in monotherapy in B-CLL, AML or ALL [23-26] did not fully confirm this data as most of the patients experienced only modest anti-leukemic activity of PIs. Moreover, the patients experienced several toxic side effects from bortezomib therapy, whereas carfilzomib was rather well tolerated.

In the cells of hematopoietic origin, the constitutive proteasome is replaced by the immunoproteasome, in which the standard $\beta 1, \beta 2$ and $\beta 5$ catalytic subunits are replaced by the inducible subunits $\beta 1 \mathrm{i}$ (LMP2), $\beta 2 \mathrm{i}$ (MECL-1) and $\beta 5 \mathrm{i}$ (LMP7) [27]. Immunoproteasome expression is noticeably induced upon stimulation by inflammatory cytokines, such as interferon- $\gamma($ IFN- $\gamma)$ and tumor necrosis factor- $\alpha$ (TNF- $\alpha)$ [28]. The primary function of immunoproteasome is to generate more hydrophobic peptides, which are more likely to be presented by HLA molecules (MHC class I molecules) [29,30], but it also plays an important role in protein homeostasis control. Not only does it regulate quality control and clearance of oxidized proteins and protein aggregates generated under cytokine-induced oxidative stress, but it also controls protein transcription and levels of transcription factors that regulate multiple signaling pathways [31].

Given the abundance of immunoproteasome in several leukemia types or myeloma cells, selective targeting of the immunoproteasome is an attractive treatment option [32]. The recent development of immunoproteasome-specific PI may further allow selective targeting of such increased immunoproteasome activity to overcome drug resistance, while sparing the vast majority of tissues not expressing the immunoproteasome, thus considerably reducing the secondary effects and toxicities related to PI treatment.

To date, the proteasome/immunoproteasome composition and activity in the most common subtypes of adult leukemia is unknown. Moreover, we lack data that compare the activity of individual proteolytic subunits of the constitutive versus the immunoproteasome to the cytotoxic activity of the approved PI or novel immunoproteasome-selective PIs. Therefore, we used a cocktail of activity-based proteasome probes (ABPs), which covalently bind to the proteolytically-active sites of the constitutive and the immunoproteasome in a way that corresponds to their catalytic activity [33], to assess the proteasome content in primary samples of patients with AML, B-CLL, B-ALL, MM and PCL. Subsequently, we related the proteasome activity to the cytotoxicity of bortezomib and carfilzomib and of the novel immunoproteasome selective inhibitors LU005i and LU035i [34]. We identified B-CLL to have exclusively high immunoproteasome activity over the constitutive proteasome activity that may be used as a novel target for the immunoproteasome-selective inhibitors. 
Moreover, the malignancies inherently resistant to immunoproteasome-selective inhibitors may be sensitized to their cytotoxic activity by the selective inhibition of the proteasome $\beta 2$ subunit.

\section{Materials and Methods}

\subsection{Patients' Samples}

Primary samples of patients with B-cell acute lymphoblastic leukemia (ALL), acute myeloid leukemia (AML), chronic B-cell lymphocytic leukemia (CLL), multiple myeloma (MM) and plasma cell leukemia (PCL) and peripheral blood mononuclear cells (PBMC) from healthy volunteers were obtained at the Clinics for Medical Oncology and Hematology, Cantonal Hospital St. Gallen, St. Gallen, Switzerland. All samples were obtained during routine diagnostic procedures after approval by the independent cantonal ethical committee and after obtaining written informed consent form in accordance with Helsinki Declaration guidelines.

B-ALL, AML, B-CLL and PCL samples were obtained from peripheral blood. B-ALL and AML samples were enriched by CD34+ selection (EasySep Human Cord Blood CD34 Positive Selection Kit II, StemCell Technologies, Vancouver, BC, Canada). B-cell CLL samples were isolated using EasySep Direct Human B-CLL Cell Isolation Kit (StemCell Technologies, Vancouver, BC, Canada). MM plasma cells samples were obtained from bone marrow aspirates, enriched by CD138+ selection using EasySep Human Whole Blood and Bone Marrow and CD138+ positive selection kit (StemCell Technologies, Vancouver, BC, Canada). PBMC were obtained by standard Ficoll gradient separation of the peripheral blood.

\subsection{Cell Culture}

Primary cells were thawed into RPMI-1640 medium (Sigma-Aldrich, Buchs, Switzerland) supplemented with $20 \%$ heat-inactivated fetal calf serum (FCS), $100 \mathrm{mg} / \mathrm{mL}$ streptomycin and $100 \mathrm{U} / \mathrm{mL}$ penicillin (all Sigma-Aldrich, Buchs, Switzerland) and seeded for further analyses.

AMO-1 cell line was obtained from commercial sources (American Type Culture Collection, ATCC/LGC, Wesel, Germany). AMO-1 wild-type and AMO-1 PSMB5KO cell lines were maintained under standard conditions in RPMI-1640 medium supplemented with 10\% FCS, $100 \mathrm{mg} / \mathrm{mL}$ streptomycin and $100 \mathrm{U} / \mathrm{mL}$ penicillin. MycoAlert Mycoplasma Detection Kit (Lonza, Basel, Switzerland) was used to rule out the mycoplasma contamination in the cell culture and the modified cell line was authenticated with its parental cell line by the STR-typing (at DSMZ, a German collection of Microorganisms and Cell Cultures, Braunschweig, Germany).

\subsection{CRISPR/Cas9 Knockout of PSMB5}

Two different short guide RNAs (sgRNAs) targeting PSMB5 gene in positions spanning the proteolytically active site were designed by web-based tool CRISPOR [35], to generate a larger deletion in PSMB5 gene, as was described before [36]. The proteolytically active site of human $\beta 5$ c subunit was obtained from UniProt database (P28074). The sequences of the sgRNAs are as follows (with the PAM sequence in italics): PSMB5_g1: CCGCTACCGGTGAACCAGCGCGGG, PSMB5_g2: TGCCTCCCAGACGGTGAAGAAGG.

Briefly, sgRNAs PSMB5_g1 and PSMB5_g2 were cloned into lentiCRISPRv2 vector plasmid carrying both Cas9 and guide RNA (a gift from Zhang's lab; Addgene plasmids \#52961). Next, separate lentiviruses for PSMB5_g1 and PSMB5_g2 were produced by packaging plasmids pMD2.G and psPAX2 (a gift from Trono's lab; Addgene plasmids $\# 12259$ and \#12260) and the lentiCRISPRv2 transfer plasmids in HEK-293-LentiX cells (Takara-Bio, Kusacu, Japan) following protocol described elsewhere [37]. AMO-1 cells were transduced with PSMB5_g1 and PSMB5_g2 viral particles in 1:1 ratio and cells with stably introduced CRISPR/Cas9 vectors were selected by puromycin $(2 \mu \mathrm{g} / \mathrm{mL}$, Sigma-Aldrich, Buchs, Switzerland). Single-cell derived colonies of AMO-1 cells were obtained using 
MethoCult Classic (\#H4434, StemCell Technologies, Vancouver, BC, Canada). The clones were screened for larger deletions in PSMB5 using PCR with primers spanning the deletion site (PSMB5_del_F: AGGAAGTGAAGCTGTGACGG and PSMB5_del_R: CGTTCCCAGAAGCTGCAATC) that produces PCR product of $1442 \mathrm{bp}$ in non-deleted PSMB5 and $250 \mathrm{bp}$ in deleted PSMB5. Sanger sequencing was performed to confirm the presence of a deletion in the on-target sequence of genome. Moreover, the clones were screened for knock-out of the $\beta 5 c$ activity by $\mathrm{ABP}$ and a single-cell derived colony with confirmed deletion and no $\beta 5 c$ activity was chosen for further analyses.

\subsection{Chemicals}

Bortezomib and carfilzomib were obtained from commercial sources (Selleck Chemicals, Houston, TX, USA). LU005i, LU035i, LU025c, LU102 and ABP were synthesized at Leiden University. Detailed information regarding proteasome inhibitors used in the study is presented in Table S1.

\subsection{Proteasome $\beta$-Subunits Profiling with Activity-Based Proteasome Probes Labelling}

Activity of proteasome subunits was assessed on a protein lysate by SDS-PAGE after $1 \mathrm{~h} / 37^{\circ} \mathrm{C}$ incubation with the set of subunit-selective activity-based probes (ABP) that differentially visualize individual activities of $\beta 1, \beta 2$ and $\beta 5$ subunits of the constitutive and the immunoproteasome, as described [33]. Protein subunits were separated by SDS-PAGE, gel images were acquired using Fusion Solo S Western Blot and Chemi Imaging System (Vilber Lourmat, Collégien, France). The quantification of the activity was performed using Fiji (open source image processing package based on ImageJ) [38]. For each sample, the ratio of activity of the immunoproteasome vs. constitutive proteasome subunits was calculated by dividing the band intensity of each of the immunoproteasome subunits by the band intensity of the corresponding constitutive proteasome subunit.

\subsection{CTG Viability Assay}

An amount of $1 \times 10^{4}$ of cells were seeded per well into a white, flat bottom 96well plate (Corning, Root, Switzerland). The cells were exposed to increasing doses of proteasome inhibitors in $100 \mu \mathrm{L}$ of standard media per well for $48 \mathrm{~h}$ and cell viability was determined using CellTiter-Glo luminescent cell viability assay (Promega, Madison, WI, USA) according to manufacturer's protocol. Only samples where the untreated controls showed high ATP production were used in the analysis. The cytotoxicity of the drugs was normalized to control — untreated cells-and for each sample a dose-response curve to each tested chemical was generated.

\subsection{Lactate Dehydrogenase Quantification}

Levels of lactate dehydrogenase ( $\mathrm{LDH}$, assessed in $\mathrm{U} / \mathrm{L}$ ) from peripheral blood of the patients were determined during patients' routine diagnostic procedures at the Cantonal Hospital, St. Gallen.

\subsection{Statistical Analysis}

Dose-response curves were generated using nonlinear fit. The $\mathrm{IC}_{50}$ of each chemical was determined using nonlinear regression analysis from dose-response curves. Ordinary one-way ANOVA with Tukey's multiple comparisons test was used for the comparison of statistically significant differences between the samples. Correlation coefficients between the activity ratios of $\beta 5 \mathrm{i} / \mathrm{c}$, the cytotoxicity of proteasome inhibitors and LDH levels were calculated using Spearman's rank correlation, and $p$ values $<0.05$ were considered as statistically significant. Statistical evaluation was performed in GraphPad Prism v8 (GraphPad Software, La Jolla, CA, USA). 


\section{Results}

\subsection{B-CLL Shows Exclusive Predominant Activity of the Immunoproteasome}

Initially, the activity of both types of proteasomes were tested in different hematological malignancies, including 16 AML, 3 B-ALL, 17 B-CLL, 6 MM and 5 PCL and in PBMC samples obtained from six healthy donors. Detailed characteristics of patients/samples included in the study is provided in Table 1.

Table 1. Basic characteristics of patients included in the study.

\begin{tabular}{cccccc}
\hline & AML & B-ALL & B-CLL & MM & PCL \\
\hline Nr of patients & 16 & 3 & 17 & 6 & 5 \\
Male-females (\%) & $62-38 \%$ & $33-67 \%$ & $65-35 \%$ & $50-50 \%$ & $20-80 \%$ \\
Age (median; min-max) & $64(32-84)$ & $35(28-38)$ & $69(54-81)$ & $74(56-84)$ & $60(51-69)$ \\
\hline
\end{tabular}

$\mathrm{AML}=$ acute myeloid leukemia, B-ALL = B-cell acute lymphoblastic leukemia, B-CLL = B-cell chronic lymphocytic leukemia, $\mathrm{MM}=$ multiple myeloma, $\mathrm{PCL}$ = plasma-cell leukemia

In each sample, activity of each of the proteolytically active $\beta$-subunits was determined by $\mathrm{ABP}$ and is expressed as a ratio between the respective immunoproteasome and the constitutive proteasome subunit $(\beta 5 \mathrm{i} / \mathrm{c}, \beta 1 \mathrm{i} / \mathrm{c}$ and $\beta 2 \mathrm{i} / \mathrm{c})$. While most of the malignancies show activity of both types of the proteasomes, B-CLL samples show increased activity of the immunoproteasome active sites $\beta 5 \mathrm{i}, \beta 1 \mathrm{i}$ and $\beta 2 \mathrm{i}$ over the corresponding $\beta 5 \mathrm{c}, \beta 1 \mathrm{c}$ and $\beta 2 \mathrm{c}$ sites (Figure $1 \mathrm{~A}-\mathrm{C}$ ). The most significant differences were observed in the activity ratios for $\beta 5$ and $\beta 2$ subunits, where B-CLL differed significantly in $\beta 5 \mathrm{i} / \mathrm{c}$ activity ratio from AML, T-ALL, MM and PCL (Figure 1A) and in $\beta 2 \mathrm{i} / \mathrm{c}$ activity ratio from AML, B-ALL, MM and PCL (Figure 1C). Deeper analysis of B-CLL cohort of patients (for basic biological and clinical information about the B-CLL cases, see Supplementary Table S2) showed that levels of lactate dehydrogenase ( $\mathrm{LDH}$ ) correlate positively with the $\beta 5 \mathrm{i} / \beta 5 \mathrm{c}$ activity ratio (Spearman $r=0.6818 ; p=0.0251$, Supplementary Figure S1A). Of note, PBMC samples show rather heterogeneous activity profile of the $\beta 5 \mathrm{i} / \beta 5 \mathrm{c}$, as they are a mixture of different cell types with different proteasome activities (as, for example, normal B-cells predominantly express $\beta 5$ i) [39]. Nevertheless, from the malignant entities of a B-cell origin, B-CLL shows a unique profile of high relative immunoproteasome activity, which is not seen in other acute or chronic B-cell malignancies and which correlates with levels of LDH, a general marker of tumor burden.

(A)

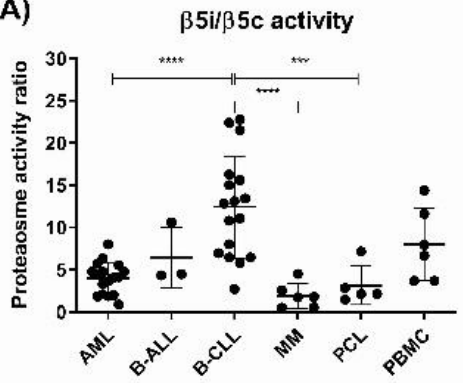

(B)

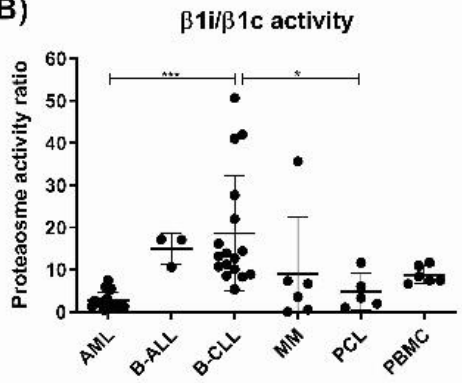

(C)

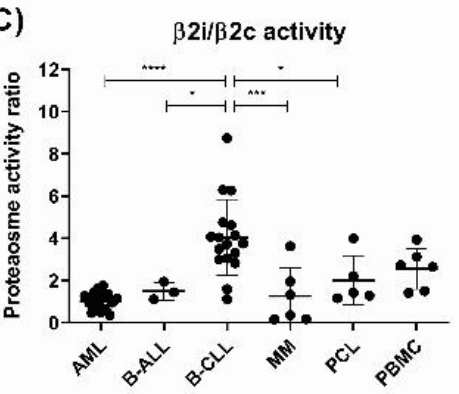

Figure 1. Profile of the activity of the immunoproteasome subunits over constitutive proteasome subunits determined by ABP labelling in different hematological malignancies. (A) Comparison between the ratio of activity of proteasome $\beta 5$ i versus $\beta 5$ c, data represent mean \pm SD. (B) Comparison between the ratio of activity of proteasome $\beta 1$ i versus $\beta 1$ c, data represent mean \pm SD. (C) Comparison between the ratio of activity of proteasome $\beta 2 \mathrm{i}$ versus $\beta 2 \mathrm{c}$, data represent mean \pm SD. In all analyses, statistical significance was obtained with ANOVA and Tukey's multiple comparison test, where ${ }^{*}$ represents $p<0.05,{ }^{* * *}$ represents $p<0.001$ and ${ }^{* * * *}$ represents $p<0.0001$. AML $=$ acute myeloid leukemia, B-ALL = B-cell acute lymphoblastic leukemia, B-CLL = B-cell chronic lymphocytic leukemia, $\mathrm{MM}=$ multiple myeloma, $\mathrm{PCL}=$ plasma-cell leukemia, $\mathrm{PBMC}=$ peripheral blood mononuclear cells. 


\subsection{B-CLL Is the Most Sensitive to Bortezomib and Carfilzomib}

The approved PIs for MM therapy are designed to target the chymotrypsin-like site ( $\beta 5$ subunit) of the constitutive and immunoproteasome, which is the most important target to inhibit proteasomal proteolysis $[40,41]$. It was later discovered that higher doses of bortezomib co-inhibit caspase-like sites (the $\beta 1$ subunits), while carfilzomib co-inhibits trypsin-like sites (the $\beta 2$ subunits). Moreover, they target the active sites of the immunoproteasome at low nanomolar doses, comparable to doses necessary for the inhibition of the active sites of the constitutive proteasome [42-44]. Therefore, we tested the cytotoxicity of bortezomib and carfilzomib in our cohort of hematological malignancies by analyzing dose-response curves and obtaining $\mathrm{IC}_{50}$ value for each sample. B-CLL was the most sensitive cohort of samples to both bortezomib and carfilzomib, supporting our previous observations (Figure 2A,B). Specifically, B-CLL samples were significantly more sensitive to bortezomib and carfilzomib than AML, which was the most resistant cohort of samples in our analysis. Importantly, only B-CLL cells were also significantly more sensitive to bortezomib and carfilzomib than PBMCs, showing an opportunity for a selective toxicity of malignant cells and less systemic toxicity associated with the use of these PIs.

A)

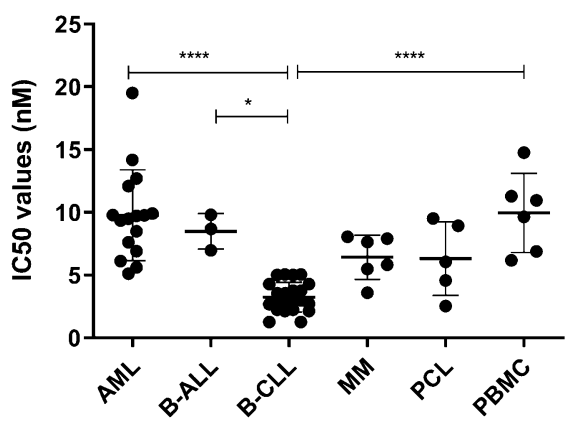

B)

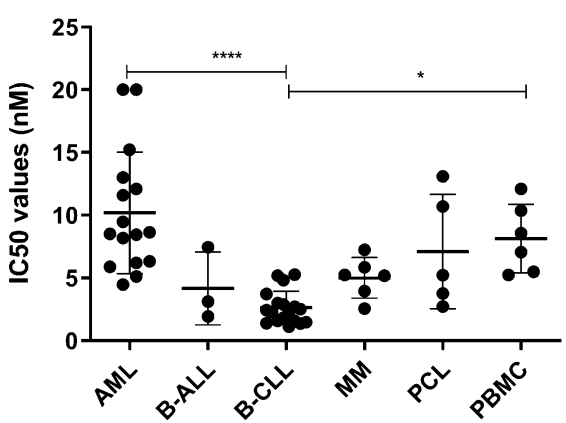

Figure 2. Profile of the $\mathrm{IC}_{50}$ values of the approved proteasome inhibitors in different hematological malignancies. (A) Comparison of $\mathrm{IC}_{50}$ values of bortezomib determined $48 \mathrm{~h}$ after the continuous treatment in various hematological malignancies, data represent mean $\pm \mathrm{SD}$. (B) Comparison of $\mathrm{IC}_{50}$ values of carfilzomib determined $48 \mathrm{~h}$ after the continuous treatment in various hematological malignancies, data represent mean \pm SD. In all analyses, statistical significance was obtained with ANOVA and Tukey's multiple comparison test, where * represents $p<0.05$ and ${ }^{* * *}$ represents $p<0.0001$. AML $=$ acute myeloid leukemia, B-ALL $=$ B-cell acute lymphoblastic leukemia, $\mathrm{B}-\mathrm{CLL}=\mathrm{B}$-cell chronic lymphocytic leukemia, $\mathrm{MM}=$ multiple myeloma, $\mathrm{PCL}=$ plasma-cell leukemia, $\mathrm{PBMC}=$ peripheral blood mononuclear cells, $\mathrm{BTZ}=$ bortezomib; $\mathrm{CFZ}=$ carfilzomib.

Nevertheless, although B-CLL is uniformly sensitive to bortezomib and carfilzomib, there was no correlation between sensitivity of the individual samples to bortezomib or carfilzomib and their $\beta 5 \mathrm{i} / \mathrm{c}$ activity ratio. This suggests that B-CLL depend on functional proteasome activity, irrespective of its type.

\subsection{Immunoproteasome-Selective Proteasome Inhibitors Are Selectively Cytotoxic in B-CLL and} Their Cytotoxicity Correlates with Immunoproteasome Activity

Since B-CLL shows the highest relative immunoproteasome activity, it could be exclusively sensitive to novel selective immunoproteasome inhibitors. These inhibitors could preserve efficacy on malignant cells, but significantly reduce treatment-emergent toxicities by sparing other tissues with little to no immunoproteasome activity [32]. First, we tested the cytotoxic activity of novel immunoproteasome inhibitors on a cohort of various hematological malignancies. We chose LU005i for selective inhibition of the immunoproteasome active subunits $\beta 5 \mathrm{i}, \beta 1 \mathrm{i}$ and $\beta 2 \mathrm{i}$ with predominant activity on $\beta 5 \mathrm{i}>\beta 1 \mathrm{i}>\beta 2 \mathrm{i}$ at low micromolar doses [34] (Supplementary Figure S2). LU005i was cytotoxic in low micromolar range (below $2.5 \mu \mathrm{M}$, where it retains the selectivity for the immunoproteasome subunits) in all 
tested hematological malignancies. Moreover, it was significantly more cytotoxic in B-CLL cells with high relative immunoproteasome activity, in contrast to AML or PCL, which keep both types of active proteasomes (Figure 3A). Cytotoxicity of LU005i correlated with the activity ratios of the $\beta 5 \mathrm{i} / \mathrm{c}$ subunit across the whole cohort of hematological malignancies tested (Figure 3B); however, we did not observe any significant correlation between the activity ratios of individual $\beta$ subunits and cytotoxicity of LU005i in B-CLL.

(A)

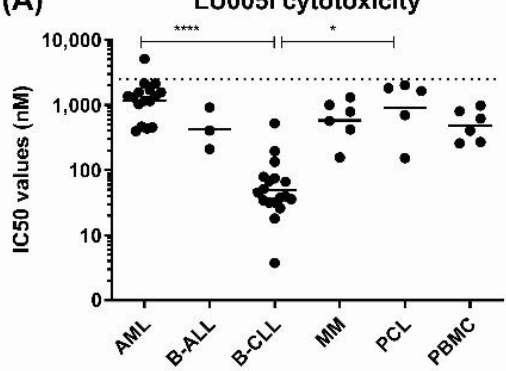

(C)

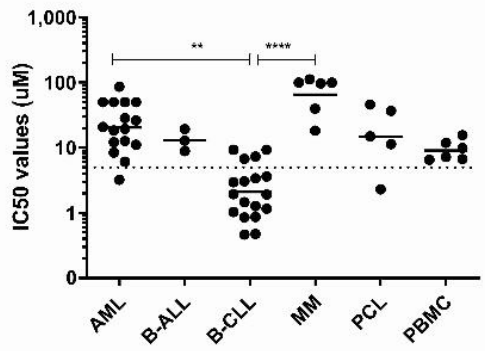

(E)

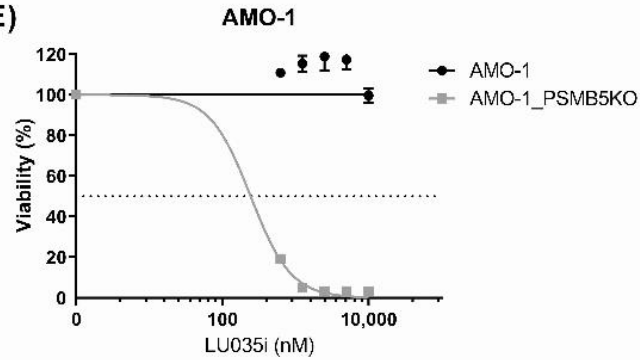

(G)

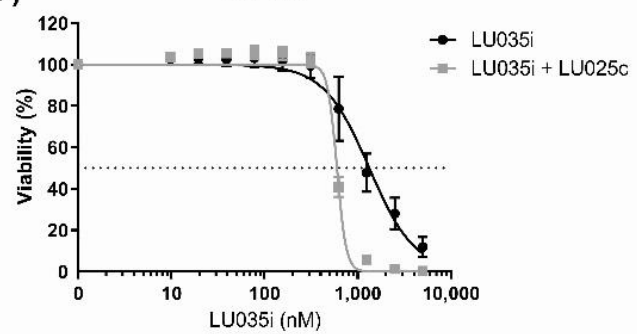

(B)

(D)
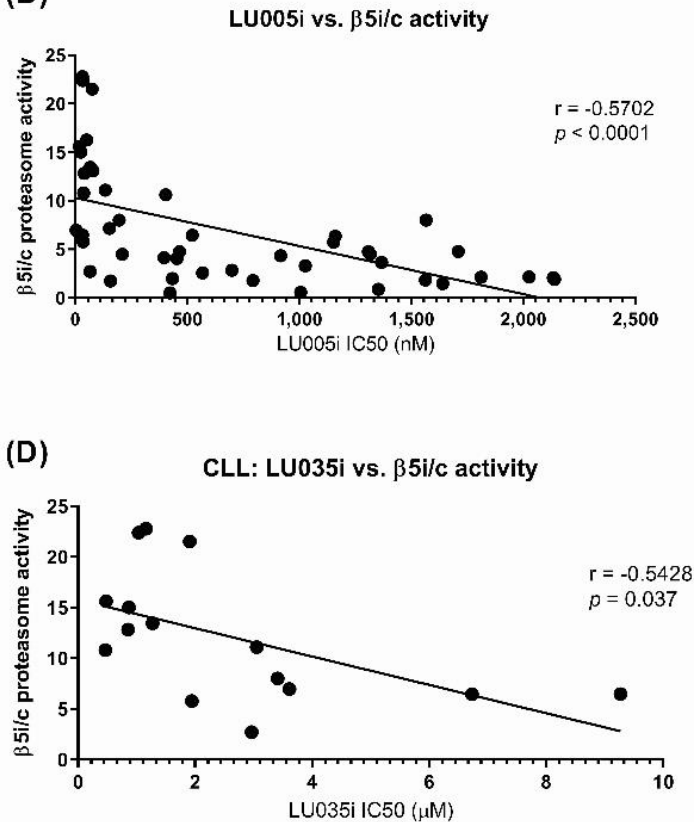

(F)

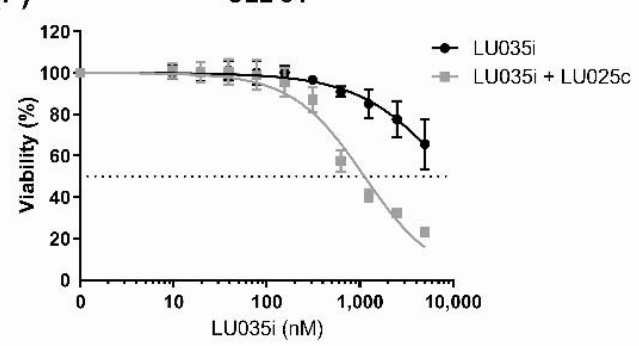

(H)

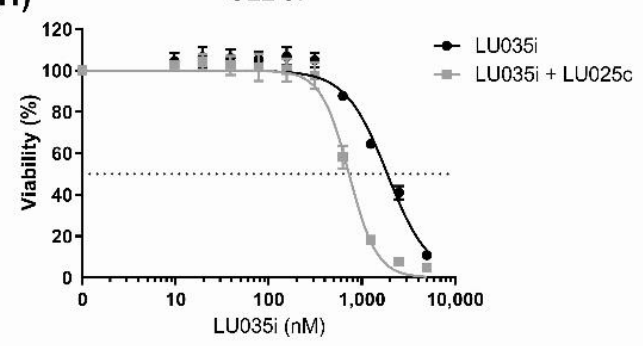

Figure 3. Cytotoxicity of the immunoproteasome-selective proteasome inhibitors in hematological malignancies. (A) Comparison of $\mathrm{IC}_{50}$ values of LU005i determined $48 \mathrm{~h}$ after the continuous treatment in various hematological malignancies. Data represent geometric mean \pm geometric $\mathrm{SD}$, statistical significance was obtained with ANOVA and Tukey's multiple comparison test, where * represents $p<0.05$ and ${ }^{* * * *}$ represents $p<0.0001$. Line represents a $2.5 \mu \mathrm{M}$ dose, to which the inhibitor retains its selectivity. (B) Correlation between the activities of constitutive vs. the immunoproteasome 
$\beta 5$ subunits and the cytotoxicity of LU005i in 15 AML, 3 B-ALL, 17 CLL, 6 MM and 5 PCL samples. Correlation and statistical significance were obtained using Spearman's rank correlation. (C) Comparison of $\mathrm{IC}_{50}$ values of LU035i determined $48 \mathrm{~h}$ after the continuous treatment in various hematological malignancies, data represent geometric mean \pm geometric SD. In samples, where the $\mathrm{IC}_{50}$ value was not reached, it was arbitrarily given an $\mathrm{IC}_{50}=100 \mu \mathrm{M}$. Statistical significance was obtained with ANOVA and Tukey's multiple comparison test, where ${ }^{* *}$ represents $p<0.01$ and ${ }^{* * *}$ represents $p<0.0001$. Line represents a $5 \mu \mathrm{M}$ dose, to which the inhibitor retains its selectivity. (D) Correlation between the activities of constitutive vs. the immunoproteasome $\beta 5$ subunits and the cytotoxicity of LU035i in 17 CLL samples. Correlation and statistical significance were obtained using Spearman's rank correlation. (E) Dose-response curves of AMO-1 and AMO-1 PSMB5 knock-out cells to LU035i determined $48 \mathrm{~h}$ after the treatment. Data represent mean $\pm \mathrm{SD}$ of three independent experiments. (F-H) Dose-response curves of three B-CLL samples to LU035i alone or in combination with $1 \mu \mathrm{M}$ LU025c determined $48 \mathrm{~h}$ after the treatment. Data represent mean \pm SD of tetraplicate. $\mathrm{AML}=$ acute myeloid leukemia, B-ALL = B-cell acute lymphoblastic leukemia, B-CLL = B-cell chronic lymphocytic leukemia, $\mathrm{MM}=$ multiple myeloma, $\mathrm{PCL}=$ plasma-cell leukemia, $\mathrm{PBMC}=$ peripheral blood mononuclear cells; LU005i = proteasome $\beta 5 \mathrm{i}+\beta 2 \mathrm{i}+\beta 1 \mathrm{i}$ selective inhibitor; LU035i = proteasome $\beta 5$ i selective inhibitor; $L U 025 c=$ proteasome $\beta 5 c$ selective inhibitor; $i=$ immunoproteasome, $c=$ constitutive proteasome.

The chymotrypsin-like site of the immunoproteasome $(\beta 5 i)$ is more hydrophobic and has different structure and size than the chymotrypsin-like site of the constitutive proteasome $(\beta 5 c)$ [45]. Therefore, it allows the design of selective $\beta 5 i$ inhibitors. Since $\beta 5 \mathrm{i}$ is rate-limiting for the proteolytic activity of the immunoproteasome, as is the $\beta 5 \mathrm{c}$ for the activity of the constitutive proteasome, we hypothesized that the sole inhibition of the $\beta 5$ i subunit activity with LU035i may be sufficient to induce cytotoxicity in cells with predominant immunoproteasome activity. LU035i is an epoxyketone-based selective PI that is selective for the inhibition of the $\beta 5 \mathrm{i}$ subunit up to $5 \mu \mathrm{M}$ concentration [34] (Supplementary Figure S3). Almost all B-CLL samples were sensitive to cytotoxic activity of LU035i at low micromolar doses (Figure 3C), in contrast to the AML, B-ALL, MM and PCL samples, suggesting that $\beta 5 \mathrm{i}$ may be a novel therapeutic target in B-CLL. Moreover, the cytotoxicity of LU035i correlated with the $\beta 5 \mathrm{i} / \mathrm{c}$ activity ratios in B-CLL (Figure 3D), whereas it could not be properly assessed in other malignancies, since the inhibitor did not reach the $\mathrm{IC}_{50}$ values here or else reached it at very high doses, where it most likely loses the $\beta 5$ i selectivity. At the same time, as we observed a positive correlation between $\beta 5 \mathrm{i} / \beta 5 \mathrm{c}$ activity ratios and levels of $\mathrm{LDH}$, we likewise observed here a negative correlation between LDH levels and IC $_{50}$ values of LU035i (Supplementary Figure S1B, Spearman $r=-0.6545, p=0.0336)$.

Previously, we have shown that in cells with both $\beta 5$ i and $\beta 5 c$ activities, inhibition of $\beta 5 \mathrm{i}$ is not cytotoxic, as the residual $\beta 5 c$ activity can substitute for inhibited $\beta 5 \mathrm{i}$ activity [12]. Since we observed the correlation between $\beta 5 \mathrm{i} / \mathrm{c}$ activity ratios and cytotoxicity of LU035i in B-CLL, we aimed to assess if the cytotoxicity of LU035i is solely related to predominant $\beta 5 \mathrm{i}$ activity or also to other factors. At the same time, we aimed to assess to what extent a presence of $\beta 5 i$ only, or both $\beta 5 i$ and $\beta 5$ c activities, affects the cytotoxicity of LU035i. Towards this aim, we first knocked-out the $\beta 5 \mathrm{c}$ activity in AMO-1 MM cell line by introducing a deletion in PSMB5, including the enzymatic active site. We subsequently obtained a single-cell derived colony with no detectable $\beta 5$ c activity, but with present $\beta 5 \mathrm{i}$ activity (Supplementary Figure S4). At the same time, we chemically inhibited the residual $\beta 5 c$ activity with selective $\beta 5 c$ inhibitor LU025c [46] in B-CLL samples, which showed lower cytotoxicity of LU035i. As expected, LU035i was not cytotoxic in AMO-1 wild-type cells up to $10 \mu \mathrm{M}$ concentration, whereas it was cytotoxic in AMO-1_PSMB5KO cells at sub micromolar doses (Figure 3E). Likewise, inhibition of residual $\beta 5 \mathrm{c}$ with LU025c sensitized B-CLL cells to LU035i (Figure 3F-H). Of note, AMO-1_PSMB5KO cells completely lacking the active $\beta 5 c$ were not sensitized to LU035i by LU025c up to $3 \mu \mathrm{M}$ concentration, whereas 
AMO-1 wt were sensitized significantly (Supplementary Figure S5A,B), confirming that the residual $\beta 5 c$ activity is the only factor affecting cytotoxicity of LU035i in malignant cells. Therefore, high relative activity of the $\beta 5 i$ subunit is a signature of B-CLL representing a novel therapeutic target for immunoproteasome $\beta 5$-selective inhibitor LU035i, associated with low cytotoxicity on cells with low relative immunoproteasome activity.

\section{4. $\beta 2$-Selective Proteasome Inhibitor Sensitizes Hematological Malignancies to $\beta 5 i$-Selective Immunoproteasome Inhibitor}

Co-inhibition of the proteasome $\beta 2 \mathrm{c}$ and $\beta 2 \mathrm{i}$ activity sensitizes MM cells to immunoproteasome inhibitor ONX-0914 [47]. Thus, we assessed if samples inherently not sensitive to $\beta 5 \mathrm{i}$ inhibition may be sensitized to LU035i by co-inhibition of the $\beta 2 c$ and $\beta 2 \mathrm{i}$ activity with selective inhibitor LU102 [48]. In living cells, LU102 sub-totally inhibits both $\beta 2 c$ and $\beta 2 \mathrm{i}$ activity at $10 \mu \mathrm{M}$ dose and retains its $\beta 2$ selectivity up to $20 \mu \mathrm{M}$ [12]. We have not observed any difference in the cytotoxicity of LU102 across different malignancies (Figure 4A). However, $2.5 \mu \mathrm{M}$ LU102, a dose not affecting the viability in most of the samples, significantly sensitized all tested hematological malignancies to low doses of LU035i, where it retains selectivity only for the $\beta 5 \mathrm{i}$ inhibition (Figure 4B-F). Moreover, LU102 alone was more cytotoxic in AMO-1_PSMB5KO cells, as compared to AMO-1 wildtype cells (Figure 4G), suggesting that lower drug doses are needed to induce cytotoxicity in the absence of $\beta 5 c$ activity. This aligns with previous data, where in the presence of $\beta 5 \mathrm{i}$ and $\beta 5 \mathrm{c}$ inhibition, lower doses of LU102 were needed to achieve complete $\beta 2 \mathrm{i}$ and $\beta 2 \mathrm{c}$ inhibition [12]. At the same time, $2.5 \mu \mathrm{M}$ dose of LU102, not affecting the viability of AMO-1 wild-type cells, significantly sensitized the cells to $\beta 5 \mathrm{i}$-selective immunoproteasome inhibitor LU035i (Figure $4 \mathrm{H}$ ). Therefore, combination of the immunoproteasome selective inhibitors with $\beta 2 c$ and $\beta 2$ i selective inhibitor allows using lower doses of both drugs to induce cytotoxicity in hematological malignancies, such as AML, MM and PCL.
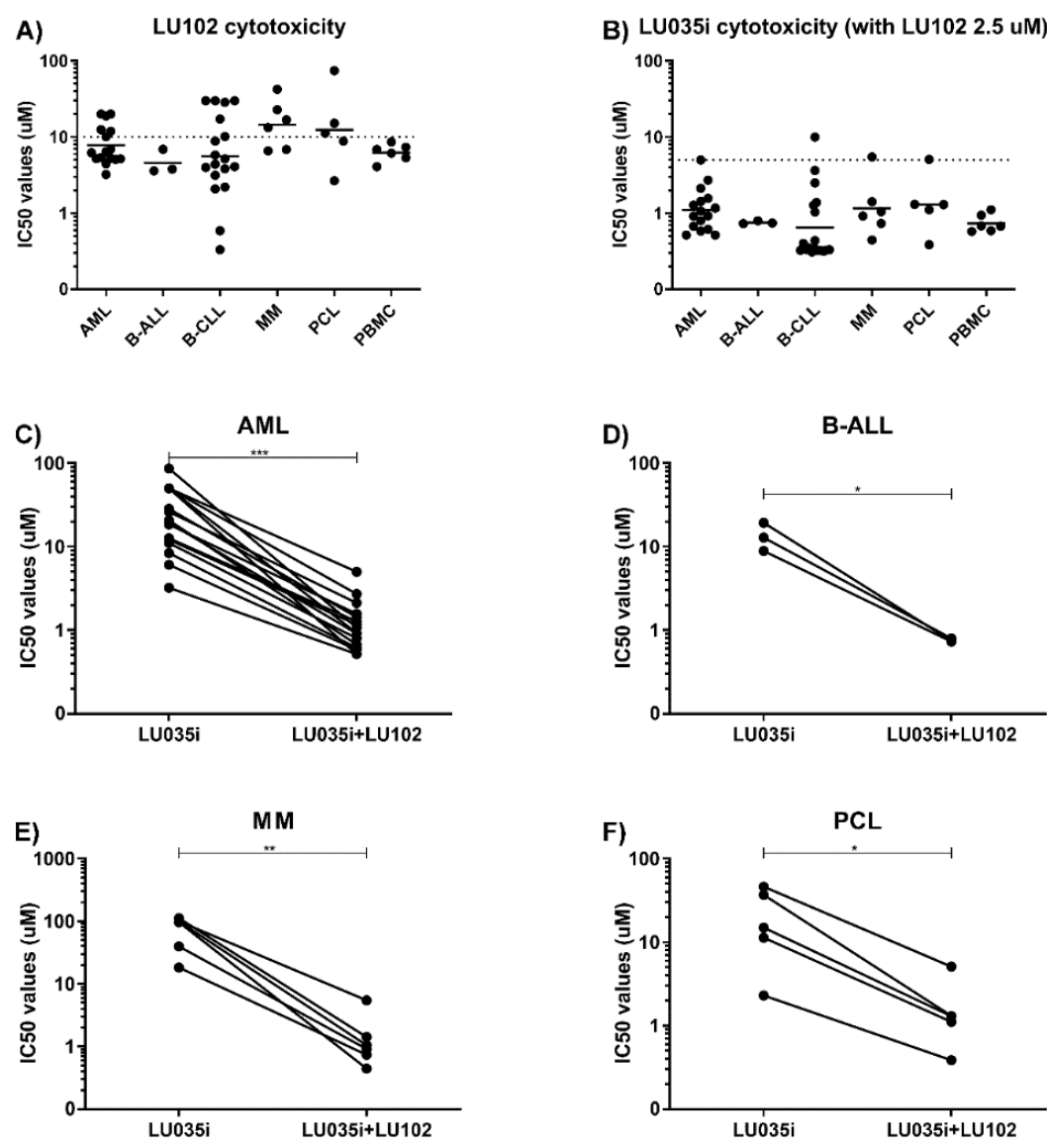

Figure 4. Cont. 

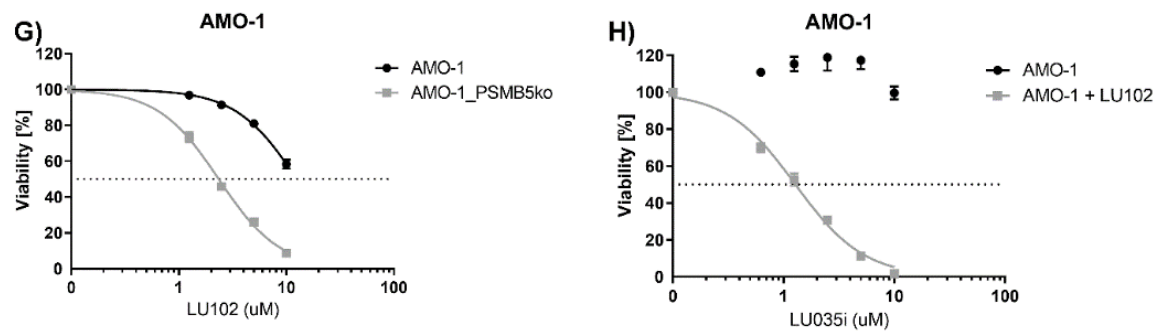

Figure 4. $\beta 2$-selective inhibitor sensitizes hematological malignancies to immunoproteasomeselective inhibitors. (A) Comparison of $\mathrm{IC}_{50}$ values of LU102 determined $48 \mathrm{~h}$ after the continuous treatment in various hematological malignancies, data represent geometric mean \pm geometric SD. Statistical significance was obtained with ANOVA and Tukey's multiple comparison test. (B) Comparison of $\mathrm{IC}_{50}$ values of LU035i combined with fixed dose of LU102 $(2.5 \mu \mathrm{M})$ determined $48 \mathrm{~h}$ after the continuous treatment in various hematological malignancies. Data represent geometric mean \pm geometric SD. Statistical significance was obtained with ANOVA and Tukey's multiple comparison test. (C) Paired comparison of $\mathrm{IC}_{50}$ values of LU035i combined with fixed dose of LU102 $(2.5 \mu \mathrm{M})$ determined $48 \mathrm{~h}$ after the continuous treatment in AML samples. Statistical significance was obtained with paired $t$-test, where ${ }^{* * *}$ represents $p<0.001$. (D) Paired comparison of $\mathrm{IC}_{50}$ values of LU035i combined with fixed dose of LU102 $(2.5 \mu \mathrm{M})$ determined $48 \mathrm{~h}$ after the continuous treatment in B-ALL samples. Statistical significance was obtained with paired $t$-test, where $*$ represents $p<0.05$. (E) Paired comparison of $\mathrm{IC}_{50}$ values of LU035i combined with fixed dose of LU102 (2.5 $\left.\mu \mathrm{M}\right)$ determined $48 \mathrm{~h}$ after the continuous treatment in MM samples. Statistical significance was obtained with paired $t$-test, where ${ }^{* *}$ represents $p<0.01$. (F) Paired comparison of $\mathrm{IC}_{50}$ values of LU035i combined with fixed dose of LU102 $(2.5 \mu \mathrm{M})$ determined $48 \mathrm{~h}$ after the continuous treatment in MM samples. Statistical significance was obtained with paired $t$-test, where * represents $p<0.05$. (G) Dose-response curves of AMO-1 wt and AMO-1 PSMB5 knock-out cells to LU102 determined $48 \mathrm{~h}$ after the treatment. Data represent mean \pm SD. $(\mathbf{H})$ Dose-response curves of AMO-1 cells to LU035i alone or in combinations with $2.5 \mu \mathrm{M}$ LU102, determined $48 \mathrm{~h}$ after the treatment. Data represent mean $\pm \mathrm{SD}$. AML $=$ acute myeloid leukemia, B-ALL = B-cell acute lymphoblastic leukemia, B-CLL = B-cell chronic lymphocytic leukemia, $\mathrm{MM}=$ multiple myeloma, $\mathrm{PCL}=$ plasma-cell leukemia, $\mathrm{PBMC}=$ peripheral blood mononuclear cells; LU035i = proteasome $\beta 5$ i selective inhibitor; LU102 = proteasome $\beta 2 c$ and $\beta 2$ i selective inhibitor; $\mathrm{i}=$ immunoproteasome, $\mathrm{c}=$ constitutive proteasome.

\section{Discussion}

Targeting immunoproteasome is a treatment strategy clinically tested in autoimmune diseases and experimentally explored in pediatric ALL or adult malignancies, such as MM [47,49-51]. Here we show that B-CLL cells possess increased activity of the immunoproteasome subunits over the constitutive proteasome active subunits, which is associated with their high sensitivity to approved PIs bortezomib and carfilzomib or novel immunoproteasome-selective inhibitors LU005i and LU035i. While bortezomib and carfilzomib inhibit both the constitutive and the immunoproteasome, they have been shown unlikely to move forward in B-CLL as a single agent given the minimal efficacy observed. At the same time, high selectivity and cytotoxic activity of LU035i in B-CLL, and significant correlation between the cytotoxicity and the immunoproteasome $\beta 5 \mathrm{i}$ activity assessed by ABP labelling suggests that proteasome inhibition is still interesting to pursue as part of combination strategies in which efficacy of another drug may be improved by inhibition of proteasome-mediated protein breakdown. Moreover, proteasome activity assessment should be used for patients' stratification and identification of patients that may benefit the most from such therapy.

The molecular mechanism underlying high immunoproteasome activity in B-CLL remains to be elucidated. The activity of the immunoproteasome can be reversibly stimulated by pro-inflammatory cytokines IFN- $\gamma$ or TNF- $\alpha$, or by reactive oxygen species (ROS) [52-55], which may potentially influence the composition of proteasome in B-CLL; however, multiple other factors may be involved. At the same time, as we observed a 
positive correlation between high relative $\beta 5 \mathrm{i} / \beta 5 \mathrm{c}$ activity and levels of $\mathrm{LDH}$, it suggests that higher relative immunoproteasome activity is associated with more severe disease and poorer prognosis [56]. Increased LDH levels are associated with poor prognosis in myelodysplastic syndromes, AML and B-CLL [57-59]. It remains to be elucidated whether immunoproteasome inhibition decreases LDH levels, a potential useful marker of disease control.

Currently, two immunoproteasome inhibitors have entered clinical evaluation for the treatment of autoimmune disorders. Both, ONX-0914 and KZR-616, are selective irreversible inhibitors of $\beta 5 \mathrm{i}$ (LMP7) and $\beta 1 \mathrm{i}$ (LMP2) sites of the immunoproteasome [60,61]. Following the discovery of their activity against autoimmune disorders, their anti-tumor activities were tested in selected groups of patients with leukemia. ONX-0914 showed activity in pediatric ALL, in contrast to rather low activity in pediatric AML [49]. More recently, ONX-0914 has been shown to be effective in pediatric T-ALL cases with $t$ (4; 11) (q21; q23) chromosomal translocation that leads to the expression of MLL-AF4 fusion protein conferring poor outcome [50]. Newly, orally bioavailable reversible immunoproteasome $\beta 5 \mathrm{i}$ inhibitor M3258 showed efficacy in diverse in vitro and in vivo MM models, a favorable safety profile and a lack of cardiac, respiratory, and neurobehavioral effects, supporting the initiation of a phase I clinical trial of M3258 in patients with relapsed/refractory MM (NCT04075721) [62,63]. In this study, we tested LU005i and LU035i irreversible immunoproteasome inhibitors, which selectively target immunoproteasome subunits over a broad concentration range up to micromolar doses [34]. Our data extend previous observations and shows that a sole inhibition of the $\beta 5 \mathrm{i}$ subunit in B-CLL is sufficient to induce cytotoxicity, which proportionally corresponds to the high relative immunoproteasome $\beta 5$ i activity ratio. At the same time, healthy PBMCs are less vulnerable to LU035i-induced cytotoxicity, thereby offering a therapeutic window at which cells expressing both types of proteasomes are spared from on-target toxicity of LU035i.

Previous data suggested that $\beta 2$ inhibition ex vivo sensitizes adult malignancies, such as MM, or pediatric B-ALL and T-ALL cases to ONX-0914 or LU035i [47,49,50]. Our data support these results and show that $\beta 2$ inhibition provided by LU102 sensitizes B-CLL cells to $\beta 5 \mathrm{i}$ inhibition provided by LU035i. More importantly, malignancies with the activity of both types of proteasomes, such as AML, B-ALL, MM or PCL, which are intrinsically resistant to LU035i, can be sensitized to its cytotoxicity by LU102. These findings offer novel therapeutic possibility for the treatment of malignancies with lack of effective therapies.

To the best of our knowledge, this is the first study showing composition and activity of proteasome/immunoproteasome in the most common adult hematological malignancies and demonstrating the exclusive activity of the immunoproteasome-selective inhibitors in B-CLL. We acknowledge the limitation of our study, which is the low number samples used in the analysis that does not allow further stratification of patients to major cytogenetically defined subgroups with different prognoses. We observed consistently low activity ratios between the constitutive vs. the immunoproteasome $\beta$-subunits in AML, MM and PCL, whereas in B-CLL, the activity ratios varied considerably from high to intermediate/low. These observations require further studies on larger cohorts of patients.

\section{Conclusions}

In conclusion, we provide a strong rationale for further in vivo studies of immunoproteasome-selective inhibitors in B-CLL, which may provide higher activity and lower off-target toxicity in combination setting with other drugs used for B-CLL therapy. At the same time, combination of immunoproteasome-selective and $\beta 2$-selective inhibitors may be effective in hematological malignancies with poor prognosis and lack of effective therapies, such as AML or PCL.

Supplementary Materials: The following are available online at https: / www.mdpi.com/article/ 10.3390 / cells11050838/s1, Figure S1: Correlation of LDH with proteasome activity and cytotoxicity of the immunoproteasome selective inhibitor in B-CLL primary samples. Figure S2: Inhibitory profile of pan-immunoproteasome selective inhibitor LU005i. Figure S3: Inhibitory profile of $\beta 5-$ 
immunoproteasome selective inhibitor LU035i. Figure S4: Profile of active proteasome $\beta$-subunits in AMO-1 wild-type cells and in AMO-1 cells with PSMB5 knock-out. Figure S5: Dose-response curves of AMO-1wild-type and AMO-1_PSMB5 knock-out cells to $\beta 5$ i inhibition in a presence or absence of the $\beta 5 c$ inhibition. Table S1: Detailed characteristics of proteasome inhibitors used in the study. Table S2: Basic biological and clinical characteristics of B-CLL cohort.

Author Contributions: Conceptualization, A.B., M.M.-L., C.D. and L.B.; methodology, A.B., M.K., E.M., H.S.O. and C.D.; software, A.B.; validation, L.B.; formal analysis, L.B.; investigation, A.B., M.K. and L.B.; resources, A.B., E.M., H.S.O., C.D. and L.B.; data curation, L.B.; writing-original draft preparation, L.B.; writing-review and editing, A.B., M.K., M.M.-L., E.M. and C.D.; visualization, L.B.; supervision, C.D.; project administration, L.B.; funding acquisition, A.B., L.B. and C.D. All authors have read and agreed to the published version of the manuscript.

Funding: This research was funded by Cantonal Hospital St. Gallen Research Committee internal grant No. 21/20.

Institutional Review Board Statement: The study was conducted according to the guidelines of the Declaration of Helsinki, and approved by the Ethics Committee of Canton St. Gallen and by Ethics Committee of Eastern Switzerland (EKSG09/057 and EKOS09/057).

Informed Consent Statement: Informed consent was obtained from all subjects involved in the study.

Data Availability Statement: There were no data deposited in publicly available data-repositories within this pro-ject. However, any data generated within this project are available upon request.

Conflicts of Interest: The authors declare no conflict of interest.

\section{References}

1. Daver, N.; Wei, A.H.; Pollyea, D.A.; Fathi, A.T.; Vyas, P.; DiNardo, C.D. New directions for emerging therapies in acute myeloid leukemia: The next chapter. Blood Cancer J. 2020, 10, 107. [CrossRef]

2. Furstenau, M.; Eichhorst, B. Novel Agents in Chronic Lymphocytic Leukemia: New Combination Therapies and Strategies to Overcome Resistance. Cancers 2021, 13, 1336. [CrossRef]

3. Chim, C.S.; Kumar, S.K.; Orlowski, R.Z.; Cook, G.; Richardson, P.G.; Gertz, M.A.; Giralt, S.; Mateos, M.V.; Leleu, X.; Anderson, K.C. Management of relapsed and refractory multiple myeloma: Novel agents, antibodies, immunotherapies and beyond. Leukemia 2018, 32, 252-262. [CrossRef]

4. Gavralidis, A.; Brunner, A.M. Novel Therapies in the Treatment of Adult Acute Lymphoblastic Leukemia. Curr. Hematol. Malig. Rep. 2020, 15, 294-304. [CrossRef]

5. Gurnari, C.; Pagliuca, S.; Visconte, V. Deciphering the Therapeutic Resistance in Acute Myeloid Leukemia. Int. J. Mol. Sci. 2020, 21, 8505. [CrossRef]

6. DeAngelo, D.J.; Jabbour, E.; Advani, A. Recent Advances in Managing Acute Lymphoblastic Leukemia. Am. Soc. Clin. Oncol. Educ. Book 2020, 40, 330-342. [CrossRef]

7. Skanland, S.S.; Mato, A.R. Overcoming resistance to targeted therapies in chronic lymphocytic leukemia. Blood Adv. 2021, 5, 334-343. [CrossRef]

8. Davis, L.N.; Sherbenou, D.W. Emerging Therapeutic Strategies to Overcome Drug Resistance in Multiple Myeloma. Cancers 2021, 13, 1686. [CrossRef]

9. Groll, M.; Heinemeyer, W.; Jager, S.; Ullrich, T.; Bochtler, M.; Wolf, D.H.; Huber, R. The catalytic sites of 20S proteasomes and their role in subunit maturation: A mutational and crystallographic study. Proc. Natl. Acad. Sci. USA 1999, 96, 10976-10983. [CrossRef]

10. Heinemeyer, W.; Fischer, M.; Krimmer, T.; Stachon, U.; Wolf, D.H. The active sites of the eukaryotic $20 \mathrm{~S}$ proteasome and their involvement in subunit precursor processing. J. Biol. Chem. 1997, 272, 25200-25209. [CrossRef]

11. Kisselev, A.F.; Akopian, T.N.; Castillo, V.; Goldberg, A.L. Proteasome active sites allosterically regulate each other, suggesting a cyclical bite-chew mechanism for protein breakdown. Mol. Cell 1999, 4, 395-402. [CrossRef]

12. Besse, A.; Besse, L.; Kraus, M.; Mendez-Lopez, M.; Bader, J.; Xin, B.T.; de Bruin, G.; Maurits, E.; Overkleeft, H.S.; Driessen, C. Proteasome Inhibition in Multiple Myeloma: Head-to-Head Comparison of Currently Available Proteasome Inhibitors. Cell Chem. Biol. 2018, 26, 340-351.e3. [CrossRef]

13. Kraus, M.; Bader, J.; Geurink, P.P.; Weyburne, E.S.; Mirabella, A.C.; Silzle, T.; Shabaneh, T.B.; van der Linden, W.A.; de Bruin, G.; Haile, S.R.; et al. The novel beta2-selective proteasome inhibitor LU-102 synergizes with bortezomib and carfilzomib to overcome proteasome inhibitor resistance of myeloma cells. Haematologica 2015, 100, 1350-1360. [CrossRef]

14. Weyburne, E.S.; Wilkins, O.M.; Sha, Z.; Williams, D.A.; Pletnev, A.A.; de Bruin, G.; Overkleeft, H.S.; Goldberg, A.L.; Cole, M.D.; Kisselev, A.F. Inhibition of the Proteasome beta2 Site Sensitizes Triple-Negative Breast Cancer Cells to beta5 Inhibitors and Suppresses Nrf1 Activation. Cell Chem. Biol. 2017, 24, 218-230. [CrossRef] 
15. Tuazon, S.A.; Holmberg, L.A.; Nadeem, O.; Richardson, P.G. A clinical perspective on plasma cell leukemia; current status and future directions. Blood Cancer J. 2021, 11, 23. [CrossRef]

16. Pahler, J.C.; Ruiz, S.; Niemer, I.; Calvert, L.R.; Andreeff, M.; Keating, M.; Faderl, S.; McConkey, D.J. Effects of the proteasome inhibitor, bortezomib, on apoptosis in isolated lymphocytes obtained from patients with chronic lymphocytic leukemia. Clin. Cancer Res. 2003, 9, 4570-4577.

17. Lamothe, B.; Wierda, W.G.; Keating, M.J.; Gandhi, V. Carfilzomib Triggers Cell Death in Chronic Lymphocytic Leukemia by Inducing Proapoptotic and Endoplasmic Reticulum Stress Responses. Clin. Cancer Res. 2016, 22, 4712-4726. [CrossRef]

18. Almond, J.B.; Snowden, R.T.; Hunter, A.; Dinsdale, D.; Cain, K.; Cohen, G.M. Proteasome inhibitor-induced apoptosis of B-chronic lymphocytic leukaemia cells involves cytochrome $\mathrm{c}$ release and caspase activation, accompanied by formation of an approximately 700 kDa Apaf-1 containing apoptosome complex. Leukemia 2001, 15, 1388-1397. [CrossRef]

19. Gupta, S.V.; Hertlein, E.; Lu, Y.; Sass, E.J.; Lapalombella, R.; Chen, T.L.; Davis, M.E.; Woyach, J.A.; Lehman, A.; Jarjoura, D.; et al The proteasome inhibitor carfilzomib functions independently of p53 to induce cytotoxicity and an atypical NF-kappaB response in chronic lymphocytic leukemia cells. Clin. Cancer Res. 2013, 19, 2406-2419. [CrossRef]

20. Fang, J.; Rhyasen, G.; Bolanos, L.; Rasch, C.; Varney, M.; Wunderlich, M.; Goyama, S.; Jansen, G.; Cloos, J.; Rigolino, C.; et al. Cytotoxic effects of bortezomib in myelodysplastic syndrome/acute myeloid leukemia depend on autophagy-mediated lysosomal degradation of TRAF6 and repression of PSMA1. Blood 2012, 120, 858-867. [CrossRef]

21. Stapnes, C.; Doskeland, A.P.; Hatfield, K.; Ersvaer, E.; Ryningen, A.; Lorens, J.B.; Gjertsen, B.T.; Bruserud, O. The proteasome inhibitors bortezomib and PR-171 have antiproliferative and proapoptotic effects on primary human acute myeloid leukaemia cells. Br. J. Haematol. 2007, 136, 814-828. [CrossRef]

22. Takahashi, K.; Inukai, T.; Imamura, T.; Yano, M.; Tomoyasu, C.; Lucas, D.M.; Nemoto, A.; Sato, H.; Huang, M.; Abe, M.; et al Anti-leukemic activity of bortezomib and carfilzomib on B-cell precursor ALL cell lines. PLoS ONE 2017, 12, e0188680. [CrossRef]

23. Faderl, S.; Rai, K.; Gribben, J.; Byrd, J.C.; Flinn, I.W.; O’Brien, S.; Sheng, S.; Esseltine, D.L.; Keating, M.J. Phase II study of single-agent bortezomib for the treatment of patients with fludarabine-refractory B-cell chronic lymphocytic leukemia. Cancer 2006, 107, 916-924. [CrossRef]

24. Awan, F.T.; Flynn, J.M.; Jones, J.A.; Andritsos, L.A.; Maddocks, K.J.; Sass, E.J.; Lucas, M.S.; Chase, W.; Waymer, S.; Ling, Y.; et al. Phase I dose escalation trial of the novel proteasome inhibitor carfilzomib in patients with relapsed chronic lymphocytic leukemia and small lymphocytic lymphoma. Leuk. Lymphoma 2015, 56, 2834-2840. [CrossRef]

25. Wartman, L.D.; Fiala, M.A.; Fletcher, T.; Hawkins, E.R.; Cashen, A.; DiPersio, J.F.; Jacoby, M.A.; Stockerl-Goldstein, K.E.; Pusic, I.; Uy, G.L.; et al. A phase I study of carfilzomib for relapsed or refractory acute myeloid and acute lymphoblastic leukemia. Leuk. Lymphoma 2016, 57, 728-730. [CrossRef]

26. Sarlo, C.; Buccisano, F.; Maurillo, L.; Cefalo, M.; Di Caprio, L.; Cicconi, L.; Ditto, C.; Ottaviani, L.; Di Veroli, A.; Del Principe, M.I.; et al. Phase II Study of Bortezomib as a Single Agent in Patients with Previously Untreated or Relapsed/Refractory Acute Myeloid Leukemia Ineligible for Intensive Therapy. Leuk. Res. Treatment. 2013, 2013, 705714. [CrossRef]

27. Murata, S.; Takahama, Y.; Kasahara, M.; Tanaka, K. The immunoproteasome and thymoproteasome: Functions, evolution and human disease. Nat. Immunol 2018, 19, 923-931. [CrossRef]

28. Niewerth, D.; Kaspers, G.J.; Assaraf, Y.G.; van Meerloo, J.; Kirk, C.J.; Anderl, J.; Blank, J.L.; van de Ven, P.M.; Zweegman, S.; Jansen, G.; et al. Interferon-gamma-induced upregulation of immunoproteasome subunit assembly overcomes bortezomib resistance in human hematological cell lines. J. Hematol. Oncol. 2014, 7, 7. [CrossRef]

29. Verbrugge, S.E.; Scheper, R.J.; Lems, W.F.; de Gruijl, T.D.; Jansen, G. Proteasome inhibitors as experimental therapeutics of autoimmune diseases. Arthritis. Res. Ther. 2015, 17, 17. [CrossRef]

30. Raule, M.; Cerruti, F.; Benaroudj, N.; Migotti, R.; Kikuchi, J.; Bachi, A.; Navon, A.; Dittmar, G.; Cascio, P. PA28alphabeta reduces size and increases hydrophilicity of 20S immunoproteasome peptide products. Chem. Biol. 2014, 21, 470-480. [CrossRef]

31. Tubio-Santamaria, N.; Ebstein, F.; Heidel, F.H.; Kruger, E. Immunoproteasome Function in Normal and Malignant Hematopoiesis. Cells 2021, 10, 1577. [CrossRef] [PubMed]

32. Kuhn, D.J.; Orlowski, R.Z. The immunoproteasome as a target in hematologic malignancies. Semin. Hematol. 2012, 49, 258-262. [CrossRef] [PubMed]

33. de Bruin, G.; Xin, B.T.; Kraus, M.; van der Stelt, M.; van der Marel, G.A.; Kisselev, A.F.; Driessen, C.; Florea, B.I.; Overkleeft, H.S. A Set of Activity-Based Probes to Visualize Human (Immuno)proteasome Activities. Angew. Chem. Int. Ed. Engl. 2016, 55, 4199-4203. [CrossRef]

34. de Bruin, G.; Huber, E.M.; Xin, B.T.; van Rooden, E.J.; Al-Ayed, K.; Kim, K.B.; Kisselev, A.F.; Driessen, C.; van der Stelt, M.; van der Marel, G.A.; et al. Structure-based design of beta1i or beta5i specific inhibitors of human immunoproteasomes. J. Med. Chem. 2014, 57, 6197-6209. [CrossRef]

35. Haeussler, M.; Schonig, K.; Eckert, H.; Eschstruth, A.; Mianne, J.; Renaud, J.B.; Schneider-Maunoury, S.; Shkumatava, A.; Teboul, L.; Kent, J.; et al. Evaluation of off-target and on-target scoring algorithms and integration into the guide RNA selection tool CRISPOR. Genome Biol. 2016, 17, 148. [CrossRef]

36. Bauer, D.E.; Canver, M.C.; Orkin, S.H. Generation of genomic deletions in mammalian cell lines via CRISPR/Cas9. J. Vis. Exp. 2015, 95, e52118. [CrossRef] [PubMed]

37. Weber, K.; Thomaschewski, M.; Benten, D.; Fehse, B. RGB marking with lentiviral vectors for multicolor clonal cell tracking. Nat. Protoc. 2012, 7, 839-849. [CrossRef] 
38. Schindelin, J.; Arganda-Carreras, I.; Frise, E.; Kaynig, V.; Longair, M.; Pietzsch, T.; Preibisch, S.; Rueden, C.; Saalfeld, S.; Schmid, B.; et al. Fiji: An open-source platform for biological-image analysis. Nat. Methods 2012, 9, 676-682. [CrossRef] [PubMed]

39. Schmidt, C.; Berger, T.; Groettrup, M.; Basler, M. Immunoproteasome Inhibition Impairs T and B Cell Activation by Restraining ERK Signaling and Proteostasis. Front. Immunol. 2018, 9, 2386. [CrossRef]

40. Kisselev, A.F.; Goldberg, A.L. Proteasome inhibitors: From research tools to drug candidates. Chem. Biol. 2001, 8, 739-758. [CrossRef]

41. Kisselev, A.F.; van der Linden, W.A.; Overkleeft, H.S. Proteasome inhibitors: An expanding army attacking a unique target. Chem. Biol. 2012, 19, 99-115. [CrossRef] [PubMed]

42. Blackburn, C.; Gigstad, K.M.; Hales, P.; Garcia, K.; Jones, M.; Bruzzese, F.J.; Barrett, C.; Liu, J.X.; Soucy, T.A.; Sappal, D.S.; et al. Characterization of a new series of non-covalent proteasome inhibitors with exquisite potency and selectivity for the $20 \mathrm{~S}$ beta5-subunit. Biochem. J. 2010, 430, 461-476. [CrossRef] [PubMed]

43. Demo, S.D.; Kirk, C.J.; Aujay, M.A.; Buchholz, T.J.; Dajee, M.; Ho, M.N.; Jiang, J.; Laidig, G.J.; Lewis, E.R.; Parlati, F.; et al Antitumor activity of PR-171, a novel irreversible inhibitor of the proteasome. Cancer Res. 2007, 67, 6383-6391. [CrossRef] [PubMed]

44. Screen, M.; Britton, M.; Downey, S.L.; Verdoes, M.; Voges, M.J.; Blom, A.E.; Geurink, P.P.; Risseeuw, M.D.; Florea, B.I.; van der Linden, W.A.; et al. Nature of pharmacophore influences active site specificity of proteasome inhibitors. J. Biol. Chem. 2010, 285, 40125-40134. [CrossRef] [PubMed]

45. Huber, E.M.; Basler, M.; Schwab, R.; Heinemeyer, W.; Kirk, C.J.; Groettrup, M.; Groll, M. Immuno- and constitutive proteasome crystal structures reveal differences in substrate and inhibitor specificity. Cell 2012, 148, 727-738. [CrossRef]

46. Xin, B.T.; de Bruin, G.; Huber, E.M.; Besse, A.; Florea, B.I.; Filippov, D.V.; van der Marel, G.A.; Kisselev, A.F.; van der Stelt, M.; Driessen, C.; et al. Structure-Based Design of beta5c Selective Inhibitors of Human Constitutive Proteasomes. J. Med. Chem. 2016, 59, 7177-7187. [CrossRef]

47. Downey-Kopyscinski, S.; Daily, E.W.; Gautier, M.; Bhatt, A.; Florea, B.I.; Mitsiades, C.S.; Richardson, P.G.; Driessen, C.; Overkleeft, H.S.; Kisselev, A.F. An inhibitor of proteasome beta2 sites sensitizes myeloma cells to immunoproteasome inhibitors. Blood Adv. 2018, 2, 2443-2451. [CrossRef]

48. Geurink, P.P.; van der Linden, W.A.; Mirabella, A.C.; Gallastegui, N.; de Bruin, G.; Blom, A.E.; Voges, M.J.; Mock, E.D.; Florea, B.I.; van der Marel, G.A.; et al. Incorporation of non-natural amino acids improves cell permeability and potency of specific inhibitors of proteasome trypsin-like sites. J. Med. Chem. 2013, 56, 1262-1275. [CrossRef]

49. Niewerth, D.; Franke, N.E.; Jansen, G.; Assaraf, Y.G.; van Meerloo, J.; Kirk, C.J.; Degenhardt, J.; Anderl, J.; Schimmer, A.D.; Zweegman, S.; et al. Higher ratio immune versus constitutive proteasome level as novel indicator of sensitivity of pediatric acute leukemia cells to proteasome inhibitors. Haematologica 2013, 98, 1896-1904. [CrossRef]

50. Jenkins, T.W.; Downey-Kopyscinski, S.L.; Fields, J.L.; Rahme, G.J.; Colley, W.C.; Israel, M.A.; Maksimenko, A.V.; Fiering, S.N.; Kisselev, A.F. Activity of immunoproteasome inhibitor ONX-0914 in acute lymphoblastic leukemia expressing MLL-AF4 fusion protein. Sci. Rep. 2021, 11, 10883. [CrossRef]

51. Besse, L.; Besse, A.; Kraus, M.; Maurits, E.; Overkleeft, H.S.; Bornhauser, B.; Bourquin, J.P.; Driessen, C. High Immunoproteasome Activity and sXBP1 in Pediatric Precursor B-ALL Predicts Sensitivity towards Proteasome Inhibitors. Cells 2021, $10,2853$. [CrossRef] [PubMed]

52. Heink, S.; Ludwig, D.; Kloetzel, P.M.; Kruger, E. IFN-gamma-induced immune adaptation of the proteasome system is an accelerated and transient response. Proc. Natl. Acad. Sci. USA 2005, 102, 9241-9246. [CrossRef]

53. Groettrup, M.; Standera, S.; Stohwasser, R.; Kloetzel, P.M. The subunits MECL-1 and LMP2 are mutually required for incorporation into the 20 S proteasome. Proc. Natl. Acad. Sci. USA 1997, 94, 8970-8975. [CrossRef] [PubMed]

54. Javitt, A.; Barnea, E.; Kramer, M.P.; Wolf-Levy, H.; Levin, Y.; Admon, A.; Merbl, Y. Pro-inflammatory Cytokines Alter the Immunopeptidome Landscape by Modulation of HLA-B Expression. Front. Immunol. 2019, 10, 141. [CrossRef] [PubMed]

55. Pickering, A.M.; Koop, A.L.; Teoh, C.Y.; Ermak, G.; Grune, T.; Davies, K.J. The immunoproteasome, the 20S proteasome and the PA28alphabeta proteasome regulator are oxidative-stress-adaptive proteolytic complexes. Biochem. J. 2010, 432, 585-594. [CrossRef]

56. Wulaningsih, W.; Holmberg, L.; Garmo, H.; Malmstrom, H.; Lambe, M.; Hammar, N.; Walldius, G.; Jungner, I.; Ng, T.; Van Hemelrijck, M. Serum lactate dehydrogenase and survival following cancer diagnosis. Br. J. Cancer 2015, 113, 1389-1396. [CrossRef]

57. Wimazal, F.; Sperr, W.R.; Kundi, M.; Vales, A.; Fonatsch, C.; Thalhammer-Scherrer, R.; Schwarzinger, I.; Valent, P. Prognostic significance of serial determinations of lactate dehydrogenase $(\mathrm{LDH})$ in the follow-up of patients with myelodysplastic syndromes. Ann. Oncol. 2008, 19, 970-976. [CrossRef]

58. Germing, U.; Hildebrandt, B.; Pfeilstocker, M.; Nosslinger, T.; Valent, P.; Fonatsch, C.; Lubbert, M.; Haase, D.; Steidl, C.; Krieger O.; et al. Refinement of the international prognostic scoring system (IPSS) by including LDH as an additional prognostic variable to improve risk assessment in patients with primary myelodysplastic syndromes (MDS). Leukemia 2005, 19, 2223-2231. [CrossRef]

59. Liu, H.; Xiong, W.; Li, H.; Lv, R.; Liu, W.; Yi, S.; Li, Z.; Qiu, L. Prognostic Significance of Serum LDH in B Cell Chronic Lymphoproliferative Disorders: A Single-Institution Study of 829 Cases in China. Blood 2016, 128, 5336. [CrossRef] 
60. Basler, M.; Lindstrom, M.M.; LaStant, J.J.; Bradshaw, J.M.; Owens, T.D.; Schmidt, C.; Maurits, E.; Tsu, C.; Overkleeft, H.S.; Kirk, C.J.; et al. Co-inhibition of immunoproteasome subunits LMP2 and LMP7 is required to block autoimmunity. EMBO Rep. 2018, 19, e46512. [CrossRef] [PubMed]

61. Zhang, C.; Zhu, H.; Shao, J.; He, R.; Xi, J.; Zhuang, R.; Zhang, J. Immunoproteasome-selective inhibitors: The future of autoimmune diseases? Future Med. Chem. 2020, 12, 269-272. [CrossRef] [PubMed]

62. Sanderson, M.P.; Friese-Hamim, M.; Walter-Bausch, G.; Busch, M.; Gaus, S.; Musil, D.; Rohdich, F.; Zanelli, U.; DowneyKopyscinski, S.L.; Mitsiades, C.S.; et al. M3258 Is a Selective Inhibitor of the Immunoproteasome Subunit LMP7 (beta5i) Delivering Efficacy in Multiple Myeloma Models. Mol. Cancer Ther. 2021, 20, 1378-1387. [CrossRef] [PubMed]

63. Sloot, W.; Glaser, N.; Hansen, A.; Hellmann, J.; Jaeckel, S.; Johannes, S.; Knippel, A.; Lai, V.; Onidi, M. Improved nonclinical safety profile of a novel, highly selective inhibitor of the immunoproteasome subunit LMP7 (M3258). Toxicol. Appl. Pharmacol. 2021, 429, 115695. [CrossRef] [PubMed] 